Word count: 8002

\title{
Environmental impacts of food losses along the entire Swiss potato supply chain - current situation and reduction potentials
}

Christian Willersinn ${ }^{1,2 *}$, Sabrina Möbius ${ }^{3,4}$, Patrik Mouron ${ }^{3}$, Jens Lansche ${ }^{3}$, Gabriele Mack ${ }^{1}$

${ }^{1}$ Agroscope, Institute for Sustainability Sciences, Research Group Socio-Economics, Tänikon 1, CH-8356

Ettenhausen, Switzerland

${ }^{2}$ ETH Zurich, Institute of Consumer Behavior, Universitätsstrasse 16, CH-8092 Zurich, Switzerland

${ }^{3}$ Agroscope, Institute for Sustainability Sciences, Research Group Life Cycle Assessment, Reckenholzstrasse 191, CH-8046 Zurich, Switzerland

${ }^{4}$ University of Hohenheim, Farm Management, Computer Applications and Business Management in Agriculture (410C), 70599 Stuttgart, Germany

*Corresponding author. Tel.: +41 5848032 32, E-mail: christian.willersinn@ agroscope.admin.ch

\begin{abstract}
Food production causes large environmental impacts. In Switzerland, more than half of the initial potato production is not directly consumed by humans but lost. To analyze the environmental impacts caused by these losses, we conducted a Life Cycle Assessment concerning the demand for nonrenewable energy resources, the global warming potential, human toxicity and ecotoxicity (terrestrial and aquatic). We allocated these environmental impacts at each stage of the Swiss potato supply chain to marketable potatoes and potato losses. Furthermore, this study investigated how potential loss reduction scenarios and various loss treatments (animal feed, biogas, incineration) might affect the total ecological performance of the supply chain. The results showed that potato losses were responsible for $39 \%$ of the total terrestrial ecotoxicity, $31 \%$ of the total potato supply chain's global warming potential, $31 \%$ of its human toxicity, $27 \%$ of its aquatic ecotoxicity and $23 \%$ of its demand for nonrenewable energy resources. The results indicated in general that environmental benefits due to the loss treatments were bigger than benefits achieved by the loss reduction scenarios. Loss treatments, in particular feeding and fermentation, could reduce the examined impacts, but not generating losses represented a better option, especially at the household stage (the impacts here were 8-42 times as high as the impacts of losses at agricultural production). A combination of loss reduction and loss treatment could overcompensate the environmental impacts caused by potato losses because potatoes may be used to substitute for other goods.
\end{abstract}




\section{Keywords}

Food loss; potato supply chain; Life Cycle Assessment; loss reduction; loss treatment

\section{Introduction}

Food losses do not only have economic, social and ethic aspects but also cause considerable environmental impacts (Scholz et al., 2015). In particular for defining food loss reduction goals, not only the quantity of food losses but also their environmental impact needs to be considered (Scholz et al., 2015). Agriculture is very resource intensive and therefore causes high environmental pressure (Moll and Watson, 2009) especially when we consider the resource use and the environmental impacts resulting from the production of inputs like fertilizers, pesticides and energy (Mouron et al., 2006). In addition, post-harvest treatments such as transportation, storage, processing, packaging and refrigeration contribute substantially to the environmental impact (Garnett, 2011; Sonesson et al., 2010). Thus, food losses do not only imply that resources get lost but that various environmentally relevant impacts are caused in vain (Scholz et al., 2015).

Although many recent studies have assessed the total environmental impacts of food production including losses (Andersson et al., 1998; Bystricky et al., 2014; Jungbluth et al., 2000; Manfredi and Vignali, 2014), we do not know to which extent these environmental impacts are caused specifically by the losses, because most of these studies do not distinguish between the sold products for human consumption and their associated losses. The aim of this study was to assess the environmental impacts of the consumed potatoes and their associated losses separately for a current potato supply chain in Switzerland for which losses and the reasons of the losses had been analyzed in a previous study (Willersinn et al., 2015). Furthermore, this study examined to which extent a number of identified potato loss reduction strategies can improve the ecological performance of the entire supply chain. Because we knew that not only reducing the quantities of food losses but also loss treatments may improve performance (Takata et al., 2012), we included three loss treatments (animal feed, biogas, incineration) in the analyses. A focus on the entire supply chain (and not just on particular stages) was required as a previous study had shown that a decrease in losses at one stage coincided with an increase in losses at another stage (Eriksson, 2012).

\section{Methods}

\subsection{Goal and scope definition}

To assess the environmental impacts and the utilization of resources, we followed the ISO standardized Life Cycle Assessment (LCA) method (ISO 14040, 2006). This method has been used frequently to identify hotspots of 
environmental impacts throughout the life cycle of a product and to support environmentally related decisions (Notarnicola et al., 2012). Within the scope of this study, we considered all processes of the entire Swiss potato supply chain (including the preparation of potatoes for meals in private households) and particularly the occurrence and the treatment (including possible substitutions for other goods) of potato losses at each stage of the supply chain. We assumed that all fresh potatoes are traded by wholesalers, then sold by retailers and finally consumed in private households. Direct marketing from Swiss farms to private consumers was neglected due to small market shares (Schmid et al., 2010). The goals of this study were:

- To analyze the environmental impacts of the various stages (from farm to final consumption) of the Swiss fresh potato supply chain. Hotspots of environmental impacts are presented.

- To simulate how possible actions and modifications defined by six loss reduction strategies could improve the ecological performance of the whole Swiss potato supply chain.

- To evaluate how loss treatments influence the results of the LCA.

\subsection{Mass flow of the current supply chain, system boundary and data sources}

Based on the results of a previous study conducted in $2014 / 2015$ by Willersinn et al. (2015), we separated the mass flow of fresh potatoes from field to plate into two paths: The first path represents the mass flow of fresh potatoes finally leading to the consumption of $1 \mathrm{~kg}$ fresh potatoes in Swiss private households. The second path represents the mass flow of the associated losses occurring at each stage of the supply chain. From these two paths, we deduced the functional unit: $1 \mathrm{~kg}$ of consumed fresh potatoes considering the losses at all stages that were associated with this finally consumed unit. For our study, we divided the whole potato life cycle into four modules ( $\mathrm{A}=$ agricultural production, $\mathrm{W}=$ wholesaler, $\mathrm{R}=$ retailer, $\mathrm{H}=$ private household $)$, according to the stages of the supply chain (Figure 1). Transportation to a module was part of the respective module. For the purposes of our study, it was crucial at which processing stage within a module the losses occur. Therefore, we subdivided module W into two phases: (a) the delivery, storage, washing and optical sorting phase and (b) the packaging phase. In addition, as not all fresh potatoes being bought will be boiled, we subdivided module H into two phases: phase (1) included transportation, storage and preparation, whereas phase (2) included the cooking and eating process. At agricultural production, we considered all used energy and emissions corresponding to cultivation inputs. Impacts that refer to the life cycle of infrastructures were not considered in order to maintain comparability with Manfredi and Vignali (2014), Jones et al. (2012), Abeliotis et al. (2013) or Karakaya and Özilgen (2011). Transports were included at agricultural production except for transportation of potato losses as we assume them to be used straight on the farms. Each following stage contained all inputs and outputs associated with all relevant 
processes. Figure 1 shows the investigated system, the system boundary and the mass flow of fresh potatoes and potato losses at each stage of a current Swiss supply chain for fresh potatoes.

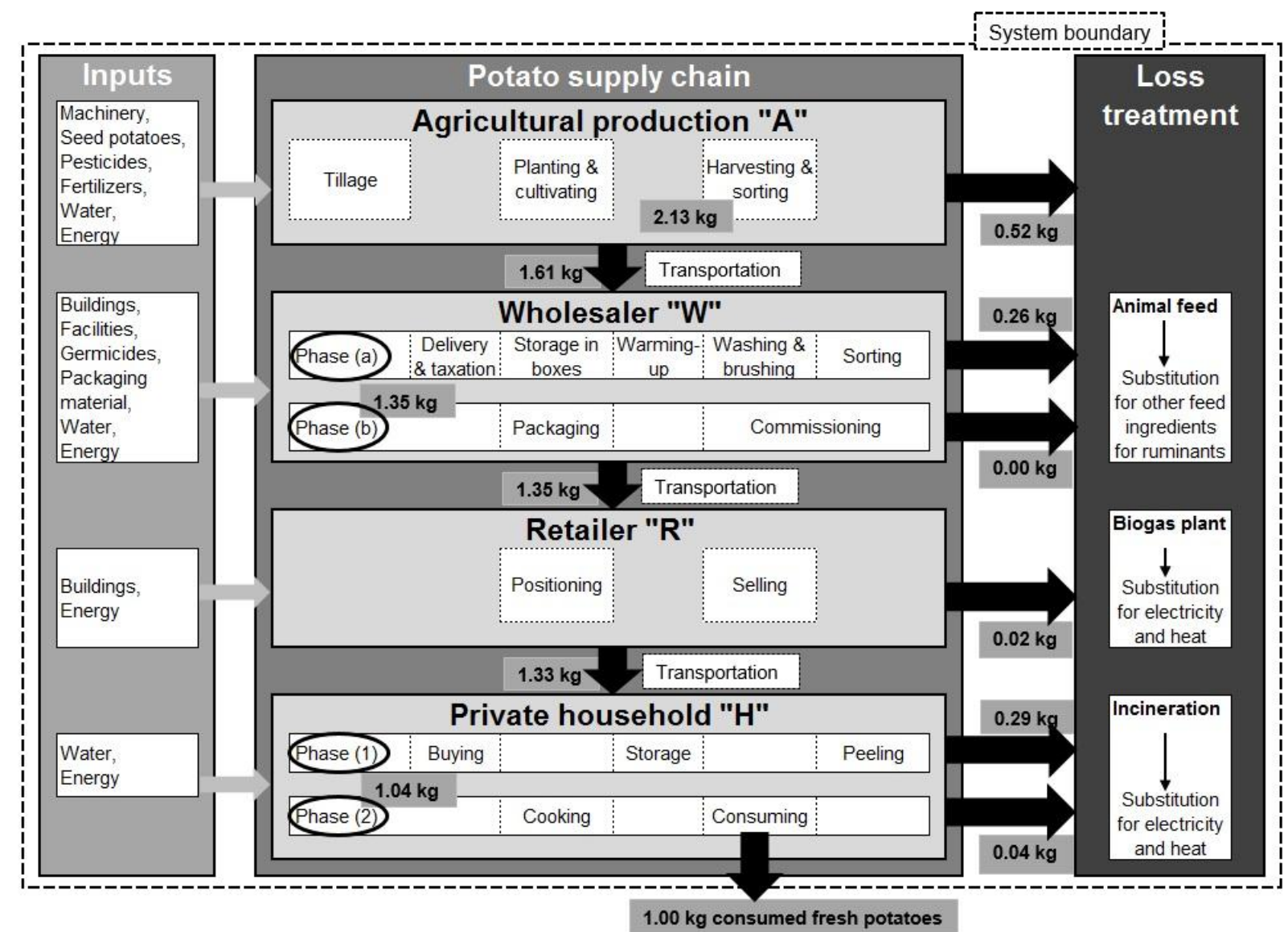

Figure 1: System boundary of the investigated system including the mass flow of fresh potatoes and potato losses to final consumption of $1 \mathrm{~kg}$ fresh potatoes in the current situation.

For the LCA study, we used data collected for a previous study (Willersinn et al., 2015) through expert interviews with supply chain participants (structured face-to-face interviews) and data provided by literature and publicly available databases. Existing databases were predominately from Switzerland or at least from other European countries.

\subsection{Definition of loss reduction scenarios}

Based on the mass flow depicted in Figure 1, we identified six loss reduction scenarios that may reduce potato loss quantities or shift losses to an earlier stage of the chain, thus improving the ecological performance of the entire potato supply chain (Table 1).

\section{Scenario A1: Pesticides against wire worms}

- Strategy: Goldor Bait (active ingredient: Fipronil) is used at the farm stage to chemically combat wire worms. Currently, Goldor Bait is applied in several areas in Germany but has been prohibited in 
Switzerland. According to Keiser et al. (2007), approximately 7\% of the total potato stock on the field is lost due to wire worms or the transmitted dry core disease. Goldor Bait is declared to have a degree of efficiency of $70 \%$ (Heger et al., 2010). Therefore, we estimated that total losses might decrease by five percentage points when Goldor Bait is applied.

- Assumptions: The loss rate at the farm stage stays constant as farmers use the nascent sorting capacity to sort out other damages which could not have been sorted out by farmers in the current situation (C). That means that farmers sort the potatoes as intensively as in the current situation. At wholesalers, where the potatoes are sorted again, the loss rate decreases as fewer defected tubers ${ }^{1}$ occur within the deliveries. At all other stages, no differences occur.

\section{Scenario A2: Improved quality sorting at farms}

- Strategy: Farmers sort their potatoes more intensively than in $\mathrm{C}$ before they deliver them to wholesalers.

- Assumptions: Farmers sort out $80 \%$ of all defected tubers [in C, they sort out $60 \%$ (Willersinn et al., 2015)]. Consequently, losses at the farm stage increase but losses at wholesalers decrease. The total loss rate stays constant, but the ecological performance might improve as losses occur earlier within the potato supply chain.

\section{Scenario A3: No quality sorting at farms}

- Strategy: No quality sorting ${ }^{2}$ at the farm stage. Quality sorting is conducted only by the wholesalers. Only losses due to overproduction ${ }^{3}$ occur at agricultural production. Through the introduction of quality classes, low-quality potatoes can be sold for reduced prices.

- Assumptions: Because consumers do not accept all kinds of defects, we applied the lower-quality specification defined by Willersinn et al. $(2015)^{4}$. Thereby, quality losses might decrease by four percentage points and still guarantee a good quality for consumers. Total losses decrease by four percentage points whereas losses at wholesalers increase and losses at agricultural production decrease.

\section{Scenario A4: Selling unwashed potatoes}

\footnotetext{
${ }^{1}$ Defected tubers are potatoes with qualitative scarcities (e.g. green tubers, rotten tubers, damages by slugs and wire worms, scab, deformities, dry core).

${ }^{2}$ Quality sorting describes the process in which potatoes are sorted according to a quality standard. Potatoes that do not pass the quality requirements are sorted out.

${ }^{3}$ Losses due to overproduction occur because potato supply is larger than demand. Due to high price differences between Swiss potato production and foreign production, exports are hardly realizable.

${ }^{4}$ This lower quality specification is a virtual quality standard that allows a few more (just skin-deep) defects than the standard quality specification.
} 
- Strategy: Potatoes are not washed and brushed. Furthermore, they are sold in a paperboard container so that no light can damage the tubers. Consequently, quality losses at wholesalers might decrease because it is not possible to sort out all defected tubers, as some of the defects are visible only after washing of the tubers.

- Assumptions: Half of all defected tubers at wholesalers can be sorted out if potatoes are not washed. Simultaneously, no losses occur at retailers as boxes are lightproof and unwashed potatoes are not as sensitive as washed ones. At private households, losses increase by two percentage points as peeling and preparation losses might increase due to defected tubers within the paperboard containers, but raw potato losses decrease as the potatoes are more suitable for storage in the lightproof boxes than in polyethylene bags.

\section{Scenario A5: Selling unpacked potatoes}

- Strategy: Retailers sell all potatoes unpacked. Customers weigh the potatoes in the stores as they are used to do with many fresh fruits and vegetables.

- Assumptions: Losses at retailers increase as customers will pick the potatoes more selectively. However, no raw potato losses at private households occur, as people purchase only as many potatoes as they need within the next days.

\section{Scenario Mix: Combination of loss reduction measures}

- Strategy: A pesticide is used to combat wire worms (A1), farmers do not sort their potatoes (A3), and potatoes will be sold unwashed (A4) and unpacked (A5).

- Assumptions: All measures described in scenarios A1-A5 can be combined but we excluded scenario A2 as it is conflictive to scenario A3, and scenario A3 reduces the total loss rate more powerfully than scenario A2 (Table 1).

Table 1: Loss rates along the supply chain in percentage of total fresh potato production on the field for the current situation and the five loss reduction strategies.

\begin{tabular}{|l|r|r|r|r|r|}
\hline Scenarios & $\begin{array}{l}\text { Agricultural } \\
\text { production }\end{array}$ & Wholesaler & Retailer & $\begin{array}{l}\text { Private } \\
\text { household }\end{array}$ & \begin{tabular}{l} 
Total \\
\hline Current situation (C)
\end{tabular} \\
\hline Pesticides against wire worms (A1) & 25 & $15^{*}$ & $1^{*}$ & $15^{*}$ & $53^{*}$ \\
\hline Improved quality sorting at farms (A2) & $\mathbf{3 0}$ & $\mathbf{7}$ & 1 & 15 & 48 \\
\hline No quality sorting at farms (A3) & $\mathbf{9}$ & $\mathbf{7}$ & 1 & 15 & 53 \\
\hline Unwashed potatoes (A4) & 25 & $\mathbf{2 4}$ & $\mathbf{0}$ & 15 & 49 \\
\hline Unpacked potatoes (A5) & $\mathbf{6}$ & 12 & $\mathbf{4}$ & $\mathbf{1 7}$ & 48 \\
\hline Combination of measures (Mix) & $\mathbf{9}$ & $\mathbf{1 2}$ & $\mathbf{4}$ & $\mathbf{1 3}$ & 38 \\
\hline
\end{tabular}

Sources: * Willersinn et al. (2015); all other data are scenario assumptions as described in the text. 


\subsection{Allocation}

Environmental impacts need to be assigned to product and co-products that occur during the production process (Klöpffer and Grahl, 2009). For each of the modules, we considered a product (marketable potatoes), which is delivered from one stage to another and finally consumed, and a co-product (potato losses), which is delivered from the respective module to a specific loss treatment (Figure 1). Allocation factors (Table 2) were calculated according to equation (1):

$\mathrm{Af}=\frac{\text { Mass }_{\text {Product }} \times \text { Price }_{\text {Product }}}{\left(\text { Mass }_{\text {Product }} \times \text { Price }_{\text {Product }}\right)+\left(\text { Mass }_{\text {Co-product }} \times \text { Price }_{\text {Co-product }}\right)}$

The allocation factors were calculated based on product prices provided by Agridea (2012). At retailer and household stage we assume that all potatoes do initially have the same quality (defected tubers had been sorted out at previous stages) and, thus, all potatoes at these stages do have the same price. The potato quantities for human consumption (product) and the losses (co-product) in the current situation originated from Willersinn et al. (2015).

Table 2: Allocation factors at each stage of the investigated potato supply chain (current situation). Prices derive from Agridea (2012), quantities from Willersinn et al. (2015).

\begin{tabular}{|c|c|c|c|c|c|c|c|}
\hline \multirow{2}{*}{\multicolumn{2}{|c|}{ Module }} & \multicolumn{2}{|c|}{$\begin{array}{c}\text { Product } \\
\text { (marketable } \\
\text { potatoes) }\end{array}$} & \multicolumn{2}{|c|}{$\begin{array}{c}\text { Co-product } \\
\text { (potato losses) }\end{array}$} & \multicolumn{2}{|c|}{ Allocation factor } \\
\hline & & $\begin{array}{c}\text { Mass } \\
(\mathrm{kg})\end{array}$ & $\begin{array}{c}\text { Price } \\
(\mathrm{CHF} / \mathrm{kg})\end{array}$ & $\begin{array}{l}\text { Mass } \\
(\mathrm{kg})\end{array}$ & $\begin{array}{c}\text { Price } \\
\text { (CHF/kg) }\end{array}$ & $\begin{array}{c}\text { Marketable } \\
\text { potatoes }\end{array}$ & Potato losses \\
\hline \multicolumn{2}{|c|}{ Agricultural production } & 1.61 & 0.47 & 0.52 & 0.06 & 0.96 & 0.04 \\
\hline \multirow{2}{*}{ Wholesaler } & Phase (a) & 1.35 & 1.63 & 0.26 & 0.06 & 0.99 & 0.01 \\
\hline & Phase (b) & 1.35 & 1.63 & 0.00 & 0.06 & 1.00 & 0.00 \\
\hline \multicolumn{2}{|l|}{ Retailer } & 1.33 & 2.00 & 0.02 & 2.00 & 0.99 & 0.01 \\
\hline \multirow{2}{*}{$\begin{array}{l}\text { Private } \\
\text { household }\end{array}$} & Phase (1) & 1.04 & 2.00 & 0.29 & 2.00 & 0.78 & 0.22 \\
\hline & Phase (2) & 1.00 & 2.00 & 0.04 & 2.00 & 0.96 & 0.04 \\
\hline
\end{tabular}

\subsection{Substitution}

Depending on the selected loss treatment, various goods can be substituted. We assumed that if potatoes are used as animal feed, they will be fed to only ruminants. Agridea (2015) developed two potential feed rations, one with potatoes and one without (Table 3). These feed rations were fed to dairy cows with a live weight of $650 \mathrm{~kg}$ and an average milk yield of $8,000 \mathrm{~kg} / \mathrm{year}$. If potato losses were to be used as animal feed, the feed ration excluding potatoes would be substituted by the feed ration including potatoes (Table 3).

Table 3: Potential feed rations for dairy cows (live weight $650 \mathrm{~kg}$; average milk yield 8,000 kg/year) including or excluding potatoes (Agridea, 2015).

\begin{tabular}{|l|r|r|}
\hline \multicolumn{1}{|c|}{ Ingredient } & \multicolumn{1}{c|}{$\begin{array}{c}\text { Quantity in a ration } \\
\text { excluding potatoes (kg) }\end{array}$} & \multicolumn{1}{c|}{$\begin{array}{c}\text { Quantity in a ration } \\
\text { including potatoes (kg) }\end{array}$} \\
\hline Potatoes (losses) & 0 & 20.0 \\
\hline Grass silage & 26.1 & 26.1 \\
\hline Field-cured hay & 3.0 & 5.0 \\
\hline Concentrate feed, 16\% crude protein & 3.8 & 2.3 \\
\hline
\end{tabular}




\begin{tabular}{|l|r|r|}
\hline Maize silage & 8.4 & 0 \\
\hline Grain maize & 2.4 & 0 \\
\hline
\end{tabular}

If potatoes were to be used in a biogas plant, we assumed for simplification that only potatoes would be used as fermentation substrate. The produced biogas would be used in a cogeneration system. Thus, electricity of the Swiss energy mix could partly be substituted, as could heat produced by natural gas. Electricity and heat would also be substituted if potatoes were to be used in an incineration plant. Detailed inventory data to model both biogas and incineration are provided in Appendix A.

For the transportation of losses from further stages of the supply chain (wholesaler and retailer) to the dairy cows or the biogas plant, we assumed the same transportation distances and methods as had been used to deliver the potatoes there. If losses occurred directly on farms, no transportation would be necessary as we assume that these losses can be used as animal feed or fermentation substrate directly on this farm. The used Ecoinvent-process to model waste incineration already includes the transportation of residual waste to the incineration plant (Jungbluth et al., 2007).

\subsection{Further Assumptions}

To conduct the LCA, some further assumptions and simplifications were necessary, as due to time and cost restrictions, it was not possible to consider all potential modifications of the Swiss potato supply chain. The assumptions that were made in the context of this study can be found in Appendix B.

\subsection{Inventory and impact assessment}

Life cycle inventory analysis aims at quantifying the resource and energy use and the emissions that are associated with the investigated system (ISO 14040, 2006). Inputs and outputs that represent less than $1 \%$ of the energy and mass flows were excluded from the analysis. The life cycle inventory with all considered inputs can be found in Appendix C.

\subsubsection{Modeling structure}

To model the supply chains, we used the Swiss Agricultural Life Cycle Assessment (SALCA) method and calculation tools for the agricultural production stage and the LCA software SimaPro 7 for the remaining stages of the supply chain. It was possible to connect all modules with each other and thus to analyze the entire supply chain (Jungbluth, 2000). Ecoinvent database v2.2 (Swiss Centre for Life Cycle Inventories, 2010) provided secondary data for our analysis (Frischknecht et al., 2007). 


\subsubsection{Agricultural production input data}

An average fresh potato yield of 39,370 kg/ha (observation period: 2001-2003) was calculated according to the details collected by Keiser et al. (2007). As several pesticides that were used within the observation period analyzed by Keiser et al. (2007) are now prohibited, we excluded from our analysis all parcels where these pesticides had been used. We included specific mineral fertilizers in SALCA as reported by Bystricky et al. (2014) to estimate their inputs and emissions. Furthermore, Keiser et al. (2007) provided a typical crop sequence including potatoes for Switzerland. The amount of water that was used for irrigation was estimated based on data provided by Keiser et al. (2007) and the Federal Statistical Office (BFS, 2012).

\subsubsection{Wholesaler input data}

Fresh potato losses at the wholesaler stage basically occur during optical sorting. We used secondary data from the Ecoinvent database to model the storage facilities. The service life of the storage and packaging buildings is 50 years (Kellenberger et al., 2007) with a construction period of 2 years (Nemecek et al., 2007). As we divided this module into two phases (see section 2.2), we had specific inputs for each of the two phases. Phase (a) included storage, washing and sorting processes and therefore required the majority of electricity [0.036 kWh/kg; source: Uhlmann et al. (2003)] and water [0.44 kg/kg; source: Willersinn et al. (2015)] in this module. For the packaging in phase (b), electricity at $0.01 \mathrm{kWh} / \mathrm{kg}$ (Uhlmann et al., 2003) and polyethylene at $3.1 \mathrm{~g} / \mathrm{kg}$ (Willersinn et al., 2015) were necessary as main inputs. During storage (phase a), germicides would be applied [0.018 g/kg; Omya AG (2009)] and cause emissions to water and air. Concerning the used machinery, we considered only the weight of the machines and the required stainless steel.

\subsubsection{Retailer input data}

We used data from the Danish LCA food database concerning the electricity for cooling and lighting or the demand for heat. We calculated the arithmetic mean between a small-sized and a large-sized supermarket of the Danish LCA food database. To estimate the share of natural gas and mineral oil to produce heat, we analyzed data from the Swiss Federal Office of Energy (BFE, 2014).

\subsubsection{Private household input data}

At private households, some assumptions were necessary (see section 2.6). The only inputs occurring at this stage would be water (1 kg/kg; own assumption) and electricity [0.27 kWh/kg; Sonesson et al. (2003)]. Furthermore, we had to model the transportation of $1 \mathrm{~kg}$ potatoes from retailer to private household [average transportation distance 
$4.7 \mathrm{~km}$ (round trip), BFS (2015); amount of groceries per shopping trip $10 \mathrm{~kg}$, Andersson et al. (1998), Jungbluth et al. (2000); 55\% of all shopping trips are made by car, Andersson et al. (1998)].

\subsection{Impact assessment}

Due to time and cost restrictions, we did not focus on all possible impact categories but selected five that we assumed to be meaningful considering potato losses. As an indicator for the resource use associated with food losses, we selected the demand for nonrenewable energy resources. Furthermore, potato losses affect environmental quality which is represented by the global warming potential (GWP), terrestrial ecotoxicity and aquatic ecotoxicity. To estimate the influence of potato losses on human health, we calculated human toxicity. The demand for nonrenewable energy resources (in MJ eq.) was calculated according to the CED method, which was launched by Ecoinvent (Hischier et al., 2010). To estimate the GWP (in $\mathrm{kg} \mathrm{CO}_{2}$ eq.), we used the IPCC method (IPCC, 2007), which calculates the emissions of greenhouse gases (e.g., $\mathrm{CO}_{2}, \mathrm{~N}_{2} \mathrm{O}, \mathrm{CH}_{4}$ ) across a time period of 100 years (Bystricky et al., 2014; Hischier et al., 2010). Terrestrial ecotoxicity, aquatic ecotoxicity and human toxicity (in kg 1.4 DB eq.) were calculated by applying the CML 2001 method (Guinée et al., 2001).

\subsection{Sensitivity analysis}

To check the influence of our modelling assumptions on the results of the study, sensitivity analyses were conducted in which we varied parameters that had meaningful impacts according to the contribution analysis. The following parameters were varied:

- At agricultural production: Amount of fertilizers and pesticides $\pm 25 \%$.

- At wholesalers: Electricity demand and the weight of machinery $\pm 25 \%$.

- At private households: Electricity demand, transportation distances and the amount of groceries per shopping trip $\pm 25 \%$.

- Whole supply chain: Price increase for potato losses from 6 to $12 \mathrm{CHF} / 100 \mathrm{~kg}$; variation of loss rate assumptions for the defined scenarios: Minimum loss rate changes that have to be realized by applying the defined measures so that none of the observed impact categories deteriorates compared with the current situation.

We always varied just one of these parameters for all of the investigated cases and left all other parameters constant. 


\section{Results}

\subsection{Environmental impact assessment}

3.1.1. Contribution analysis for the current situation

The contribution analysis focused on the current situation and should provide a rough overview of the environmental hotspots along the supply chain. All specifications below refer to the functional unit. Figure 2 presents the contribution of total impacts from all examined stages of the supply chain for all investigated categories. It compares results for three situations, namely, losses do not occur (hypothetical), losses are treated (current situation), or losses are not treated (hypothetical).

Concerning the demand for nonrenewable energy resources, private households were the main contributor (54\% of total impact in this category). Transportation of potatoes to the household required $2.01 \mathrm{MJ}$ eq. whereas 2.40 MJ eq. were used for boiling of the potatoes. The main contributor to the GWP was agricultural production (49\% of total GWP), where the production of fertilizers (0.059 $\mathrm{kg} \mathrm{CO}$ eq.) and direct emissions $\left(\mathrm{CO}_{2}, \mathrm{~N}_{2} \mathrm{O}\right)$ ( $0.083 \mathrm{~kg} \mathrm{CO}_{2}$ eq.) had significant impacts. Private households also contributed greatly to the GWP and caused in total $0.176 \mathrm{~kg} \mathrm{CO}_{2}$ eq. (37\% of total GWP) of which $0.129 \mathrm{~kg} \mathrm{CO}_{2}$ eq. were caused during transportation from retailer to household. The main contributor to human toxicity was agricultural production with in total $0.107 \mathrm{~kg} 1.4 \mathrm{DB}$ eq. (49\% of total human toxicity), mainly through machine use and manufacturing (0.050 kg 1.4 DB eq.), fertilizers (0.020 kg $1.4 \mathrm{DB}$ eq.) and seed potato production (0.017 $\mathrm{kg} 1.4 \mathrm{DB}$ eq.). Terrestrial ecotoxicity was almost exclusively caused by agricultural production (95\% of total terrestrial ecotoxicity), especially through direct field emissions (7.35E-04 kg 1.4 DB eq.) and seed potato production (1.54E$04 \mathrm{~kg} 1.4 \mathrm{DB}$ eq.). The main contributor to aquatic ecotoxicity was the household (46\% of total aquatic ecotoxicity), mostly through transportation from retailer to household (0.0261 kg $1.4 \mathrm{DB}$ eq.) and electricity used for boiling of the potatoes (0.0203 $\mathrm{kg} 1.4 \mathrm{DB}$ eq.)

Table 4 shows the environmental impact of $1 \mathrm{~kg}$ potatoes in three loss treatments as well as the impacts of loss transportation. From Willersinn et al. (2015), we knew that in Switzerland practically all losses occurring at agricultural production are used as animal feed. At the wholesaler stage, $91 \%$ of the potato losses are fed to animals whereas $9 \%$ are used in a biogas plant. Losses occurring at retailers are mainly brought to an incineration plant (68\% of all retailer losses) whereas the remaining $32 \%$ are brought to a biogas plant. For private households, Willersinn et al. (2015) found that $95 \%$ of all potato losses are thrown away (we assumed that all these losses are put into the residual waste bin) and the remaining 5\% are fed to animals. In most cases, these 5\% are fed to pets 
and not to farm animals. Hence, we assumed in the present analysis that all losses occurring at private households were used in an incineration plant.

Table 4: Impacts of three loss treatments for $1 \mathrm{~kg}$ fresh potatoes.

\begin{tabular}{|l|c|c|c|c|c|}
\hline \multirow{2}{*}{\begin{tabular}{l} 
Impact category \\
\cline { 2 - 5 }
\end{tabular}} & \multicolumn{2}{|c|}{ Impact of loss treatment } & \multicolumn{2}{c|}{$\begin{array}{c}\text { Impact of loss transportation } \\
\text { from... to farms/biogas plant* }\end{array}$} \\
\cline { 2 - 6 } $\begin{array}{l}\text { Demand for nonrenewable } \\
\text { energy resources (MJ eq.) }\end{array}$ & -0.8621 & -4.8032 & -3.4448 & 0.1465 & 0.3079 \\
\hline $\begin{array}{l}\text { Global warming potential } \\
\text { (kg CO eq.) }\end{array}$ & -0.1198 & -0.1265 & -0.1622 & 0.0093 & 0.0190 \\
\hline $\begin{array}{l}\text { Human toxicity } \\
\text { (kg 1.4 DB eq.) }\end{array}$ & -0.0500 & -0.0340 & 0.0013 & 0.0116 & 0.0131 \\
\hline $\begin{array}{l}\text { Terrestrial ecotoxicity } \\
\text { (kg 1.4 DB eq.) }\end{array}$ & $-1.34 \mathrm{E}-03$ & $-1.44 \mathrm{E}-05$ & $9.62 \mathrm{E}-06$ & 0.0000 & 0.0000 \\
\hline $\begin{array}{l}\text { Aquatic ecotoxicity } \\
\text { (kg 1.4 DB eq.) }\end{array}$ & -0.0424 & -0.0248 & 0.0575 & 0.0024 & 0.0031 \\
\hline
\end{tabular}

${ }^{*}$ Impacts of loss transportation $(1 \mathrm{~kg})$ are relevant only for the wholesaler and retailer stages as these losses need to be brought to farms or a biogas plant. Losses at private households are disposed of via residual waste and thus transported to an incineration plant. The impacts of these transports are already included in the value of incineration.

The demand for nonrenewable energy resources related to $1 \mathrm{~kg}$ of consumed potatoes was reduced by approximately one quarter and the GWP by approximately one third through today's treatment of potato losses as compared with a hypothetical reference situation without any treatment. For terrestrial ecotoxicity, loss treatment was beneficial especially due to the feeding of potato losses because other feed ingredients that have higher impacts on terrestrial ecotoxicity could be substituted. Furthermore, Figure 2 displays the environmental impacts of a hypothetical (perfect) supply chain where losses do not occur. For all observed impact categories except the terrestrial ecotoxicity, preventing losses would lead to a better ecological performance of the entire supply chain than treating potato losses (as fewer potatoes need to be produced to finally consume $1 \mathrm{~kg}$ ). By contrast, no treatment of losses would cause higher environmental impacts in all categories than treatment of losses.

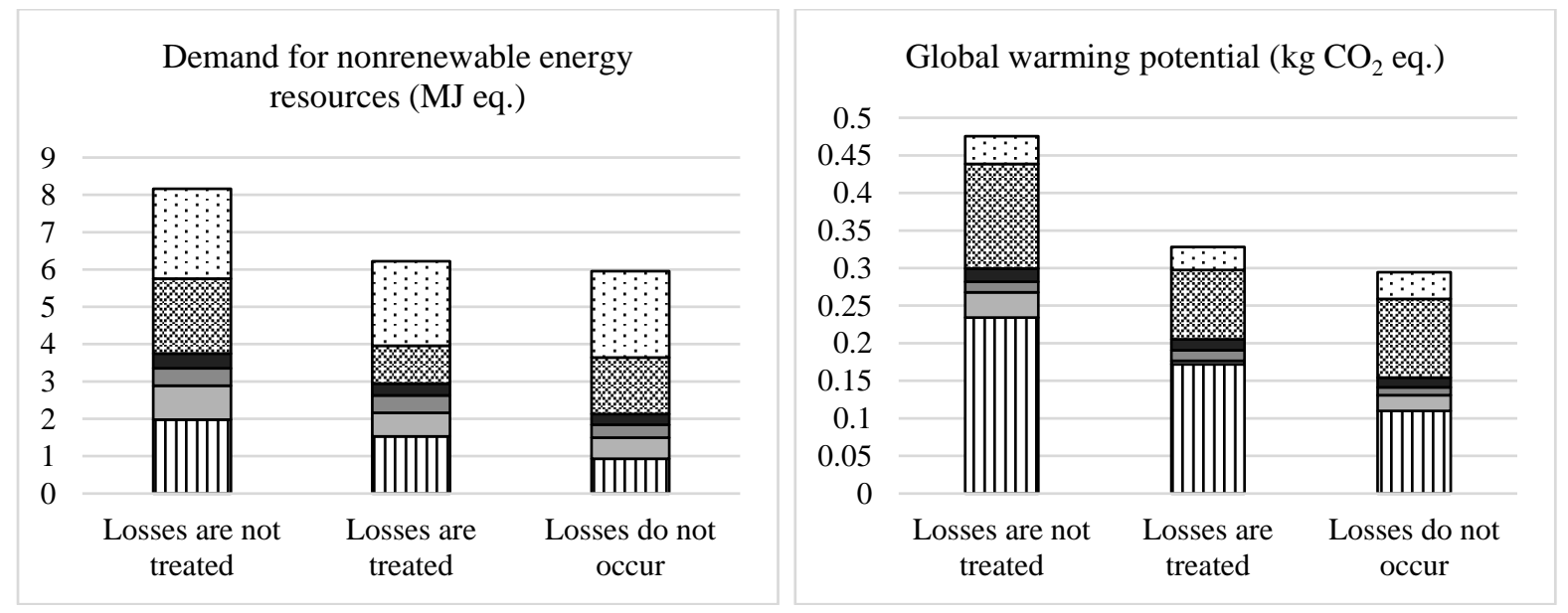




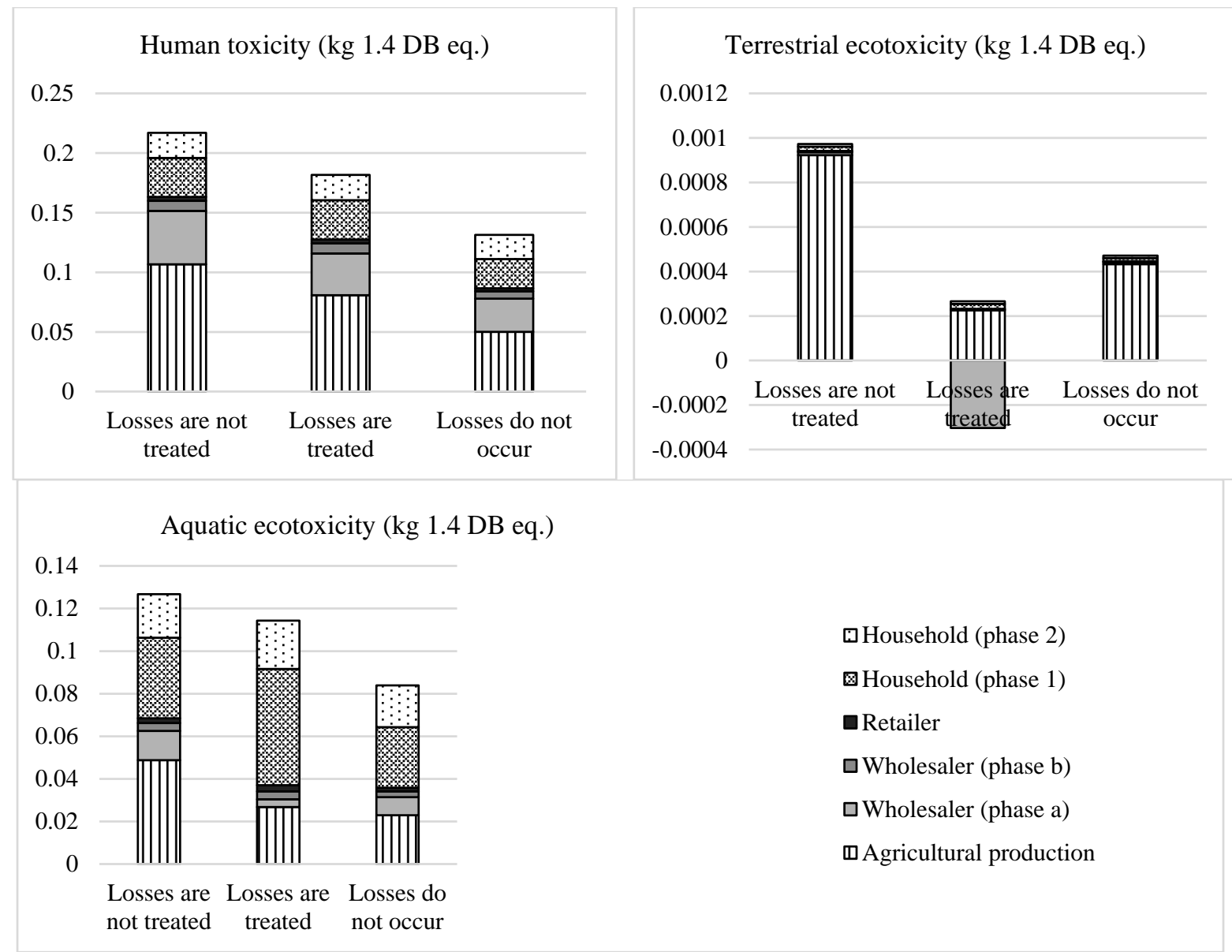

Figure 2: Contribution of the supply chain stages to environmental impact categories per kilogram of consumed potatoes for the current situation without/with consideration of current loss treatments.

\subsubsection{Impacts of loss reduction scenarios}

Through the application of the various loss reduction scenarios depicted in Table 1, loss quantities that occur across the entire supply chain to the final consumption of $1 \mathrm{~kg}$ fresh potatoes ranged from $0.92 \mathrm{~kg}$ in scenario A1 (pesticide against wire worms) to $1.13 \mathrm{~kg}$ in scenario A2 (improved quality sorting at farms) compared with $1.13 \mathrm{~kg}$ in the current situation. If we apply the combination of the scenarios A1 and A3-A5 (scenario Mix) just $0.62 \mathrm{~kg}$ of potatoes will be lost across the supply chain to finally consume $1 \mathrm{~kg}$. As fewer potatoes would have to be produced, transported and handled, the environmental impacts caused by the total supply chain partly decreased in response to the loss reduction scenarios, as indicated in Figure 3. The application of the mixed scenario (Mix) decreased all examined impacts most effectively ( -7 to $-21 \%$ ). Selling unwashed potatoes (scenario A4) and selling unpacked potatoes (scenario A5) improved the ecological performance of the entire supply chain only slightly, even if fewer potatoes were necessary for a final consumption of $1 \mathrm{~kg}$. In both cases, use of paperboard containers (recycling material) caused higher impacts than use of polyethylene bags. Eliminating quality sorting at farms (scenario A3) improved the ecological performance in all observed impact categories considerably ( -2 to $-8 \%$ ) as well as the use of pesticides against wire worms (scenario A1; -4 to $-9 \%$ ), whereas fewest improvements 
occurred by intensifying sorting (scenario A2). Detailed analysis of potato losses at each stage of the supply chain and for each loss reduction strategy is provided in Appendix D and Appendix E. The differences between loss impacts at a particular supply chain stage and for several loss reduction strategies were small and are not presented here.

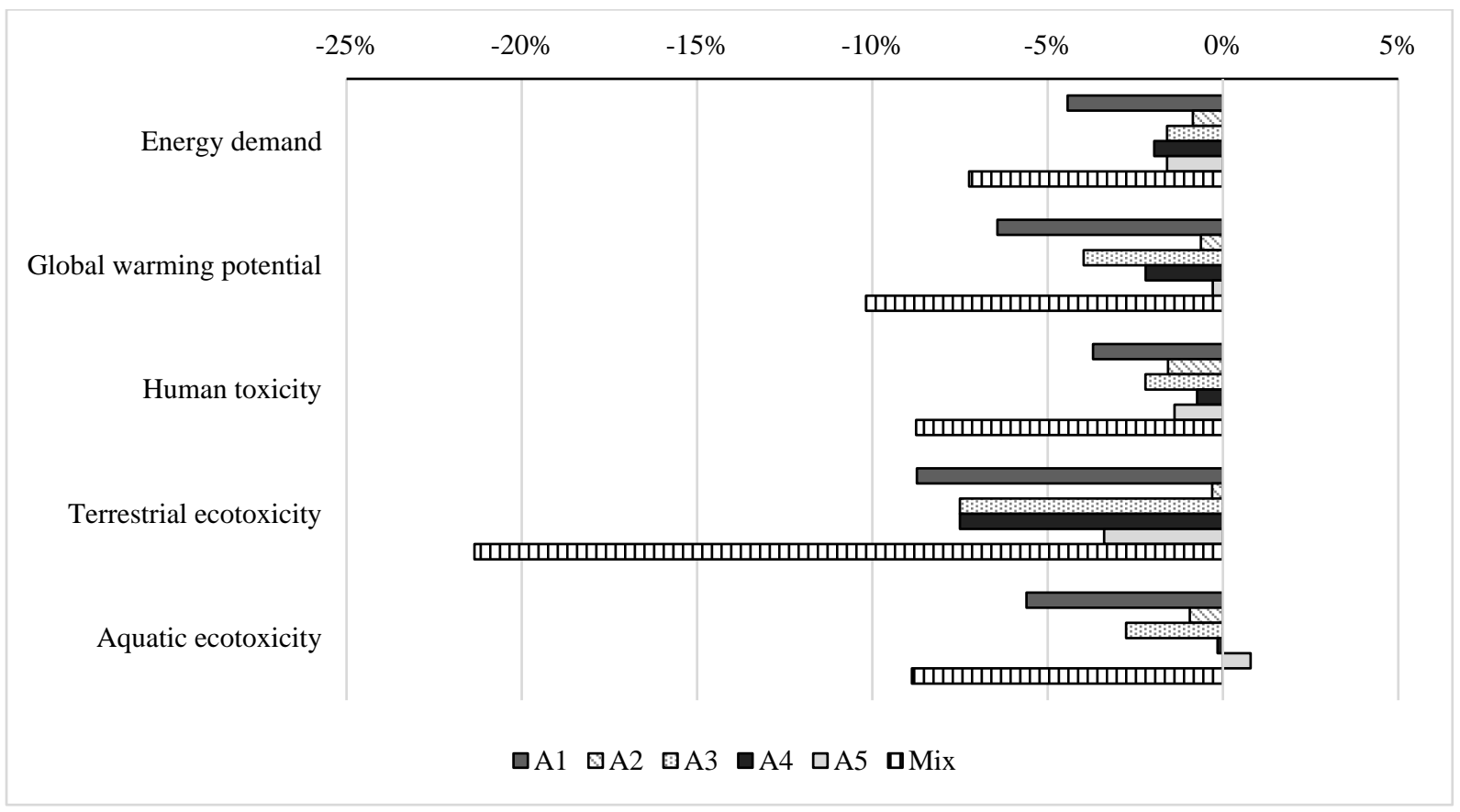

Figure 3: Variations of environmental impacts due to the loss reduction strategies relative to the current situation. A1 = Pesticides against wire worms; $A 2=$ improved quality sorting at farms; $A 3=$ no quality sorting at farms; A4 = selling unwashed potatoes; $A 5=$ selling unpacked potatoes; Mix = combination of measures .

\subsubsection{Influence of loss treatments}

Figure 4 shows the effect of a combination of all three loss treatments as is the status quo in Switzerland and scenarios in which all losses occurring in the supply chain were used as animal feed, in a biogas plant or in an incineration plant. Considering all selected impact categories, the feeding of potato losses to animals might be the best option. This treatment was found to reduce energy demand, GWP, human toxicity and aquatic ecotoxicity by $10-36 \%$ and to overcompensate total terrestrial ecotoxicity. Incineration of all potato losses would increase human toxicity as well as terrestrial and aquatic ecotoxicity (mainly due to landfilling of slag). However, the current combination of all three loss treatments (see section 3.1.1) led to considerable impact reductions in all observed impact categories ( -10 to $-104 \%)$ as compared with no loss treatment. 


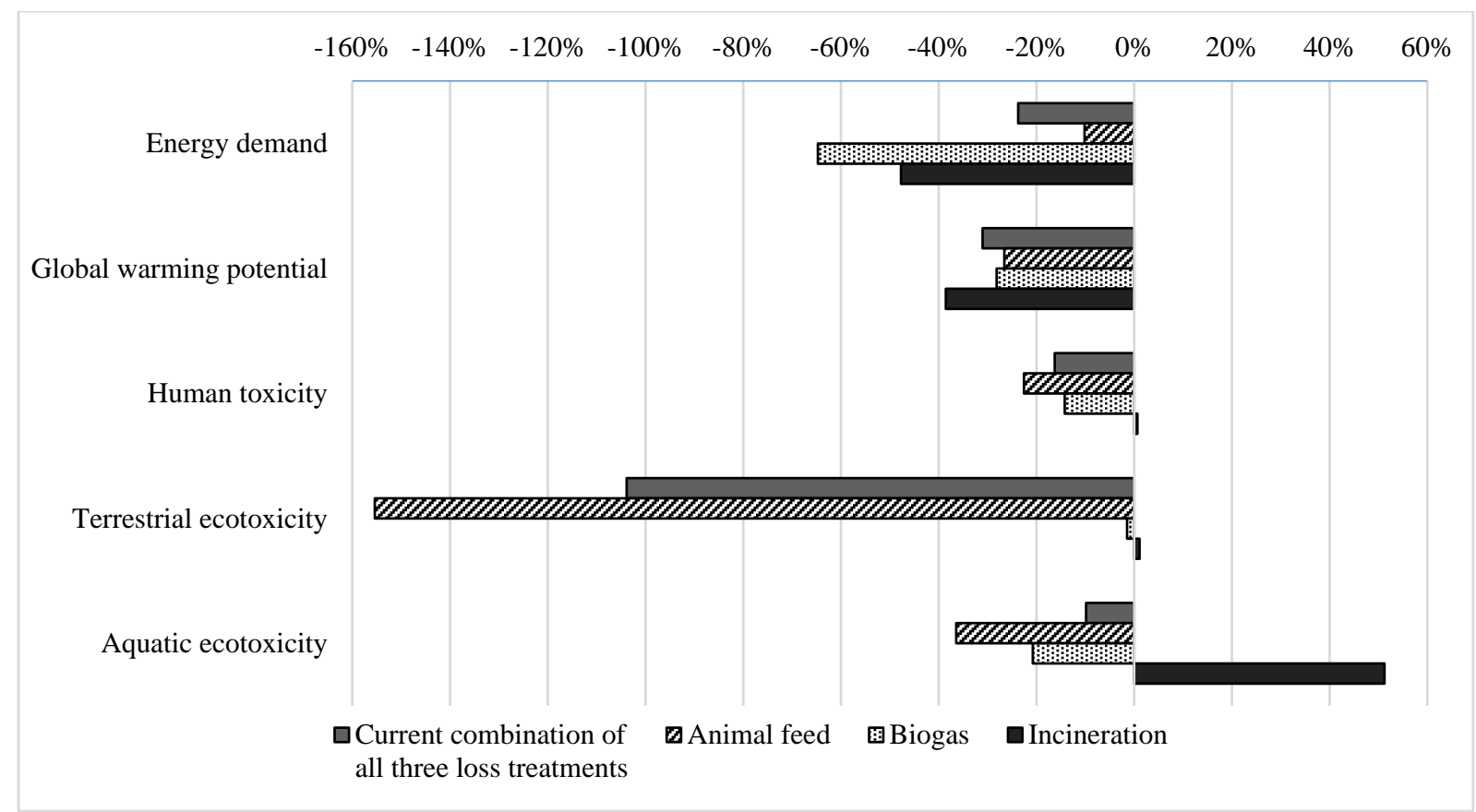

Figure 4: Changes of environmental impacts due to loss treatments relative to a hypothetical situation without loss treatment.

As the impacts of potato losses (relative to $1 \mathrm{~kg}$ of consumed potatoes) were shown to deviate from stage to stage, it is crucial where losses occur. Figure 4 indicates variations in total supply chain impacts. For stage-specific data see Appendix F. If losses occurred early in the supply chain and were used as animal feed, in a biogas plant or in an incineration plant, net benefits could be realized in almost all cases. If losses occurred further down the supply chain, the benefits from loss treatments usually could not compensate the increase in negative environmental impacts.

\subsection{Sensitivity analyses}

The results of the sensitivity analysis are presented in Figure 5. Variations of model assumptions at early stages of the potato supply chain caused relatively small deviations of total supply chain impacts. If we changed model assumptions at the household stage (transportation distance, electricity for cooking, and amount of groceries per shopping trip), the variability of the final results increased for all the observed impact categories except for terrestrial ecotoxicity. Fortunately, these uncertainties concerning the model assumptions especially at the household stage did not affect the main aim of the study: the curves in the five graphs shown in Figure 5 run more or less parallel, which means that the ranking between the various loss reduction scenarios and the status quo stays relatively constant. 


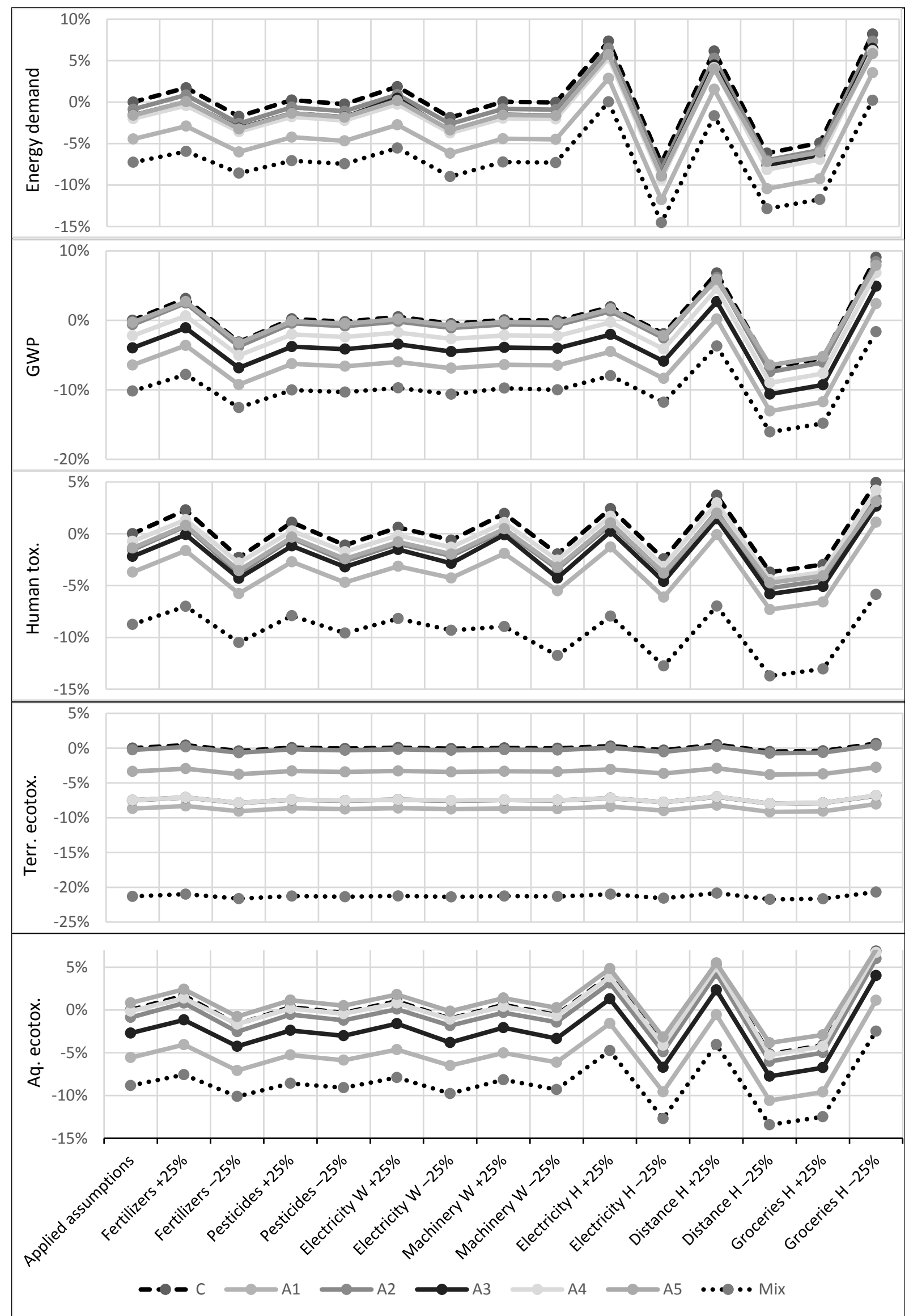

Figure 5: Sensitivity analysis of total supply chain impacts by varying the most impactful model assumptions. Al = Pesticides against wire worms; $A 2$ = improved quality sorting at farms; $A 3=$ no quality sorting at farms; $A 4=$ selling unwashed potatoes; A5 = selling unpacked potatoes; Mix = combination of measures. 
Allocation of environmental impacts to product (potatoes) and co-product (potato losses) played an essential role in the analysis. To check the price sensitivity, we increased the price for potato losses (in Switzerland, farmers get money for the unmarketable tubers as they will be sold as animal feed) at the agricultural production and wholesaler stages by $100 \%$. Consequently, the total environmental impacts of the entire supply chain stayed constant, but the impacts of potato losses increased and simultaneously the impacts of the consumed potatoes decreased. Nonetheless, the results were robust regardless of price changes. A 100\% price jump for unmarketable potatoes led to small variations in potato loss impacts between 0 and $+3 \%$ (for detailed information see Appendix G; Table A8).

Furthermore, we tested the robustness of the scenario results with regard to estimated changes in supply chain losses. To do so, we calculated how much, at minimum, the estimated loss rates needed to be reduced so that none of the observed impact categories deteriorated (Table 5). Especially scenario A1 and the mixed scenario were still favorable even if the loss rate reduction was considerably lower than expected.

Table 5: Maximum loss rates (minimum loss rate reduction compared with the current situation) under the condition that none of the observed impact categories deteriorates.

\begin{tabular}{|l|r|r|}
\hline Scenario & $\begin{array}{l}\text { Estimated loss rate (loss } \\
\text { reduction) }\end{array}$ & $\begin{array}{l}\text { Maximum loss rate so that none of } \\
\text { the observed impact categories } \\
\text { worsens (minimum loss reduction) }\end{array}$ \\
\hline Pesticides against wire worms (A1) & $48(-5)$ & $51(-2)$ \\
\hline Improved quality sorting at farms (A2) & $53(0)$ & $53(0)$ \\
\hline No quality sorting at farms (A3) & $49(-4)$ & $50(-3)$ \\
\hline Unwashed potatoes (A4) & $48(-5)$ & $49(-4)$ \\
\hline Unpacked potatoes (A5) & $51(-2)$ & $50(-3)$ \\
\hline Combination of measures (Mix) & $38(-15)$ & $44(-9)$ \\
\hline
\end{tabular}

\section{Discussion}

\subsection{Uncertainties, comparability and data quality}

According to Björklund (2002), differences among studies are often related to variations between assessment methods or differences in system boundaries. Thus, the comparability between our findings and results from other studies might be limited. For example, Ponsioen and Blonk (2011) calculated a GWP of $0.52 \mathrm{~kg} \mathrm{CO}_{2}$ eq. per kilogram consumed potatoes whereas Gruber et al. (2014) calculated a GWP of $0.95 \mathrm{~kg} \mathrm{CO}_{2}$ eq. per kilogram consumed potatoes. These values are 9\% and 100\% higher, respectively, than our results. Gruber et al. (2014) and Ponsioen and Blonk (2011) used different assumptions regarding the transportation distance from consumers to retailers and the groceries purchased per shopping trip. Furthermore, Gruber et al. (2014) considered the human 
metabolism, which we excluded from our analyzed system. Our data mainly referred to Switzerland. Transportation distances and transportation methods were assessed by expert interviews in Switzerland and with the aid of data from the Swiss Federal Statistical Office (BFS, 2015), whereas the studies mentioned above focused on other geographical areas and included other processes.

\subsection{Loss reduction and reduction of environmental impacts}

Scholz et al. (2015) highlighted the importance of not just quantifying food losses by mass but also considering the environmental impacts, as they vary greatly between foods. They found that potato losses occurred in high amounts whereas their carbon footprint was lower compared with dairy products and meat (Scholz et al., 2015). In our analyses, the $53 \%$ potato losses occurring across the entire supply chain caused $23-39 \%$ of the observed environmental impacts (without loss treatment). The analyzed loss reduction scenarios could improve the ecological performance only moderately. According to the allocation method, the environmental impacts of the potato losses were rather low, especially at early stages of the potato supply chain. Thus, the potential environmental improvements through the assumed loss reduction scenarios were relatively low at these early stages, but due to high absolute loss quantities, they still were considerable. For example, based on the Swiss potato yield in 2013, the application of strategy A3, which basically focused on the first two stages of the potato supply chain, would lead to a nationwide loss reduction of approximately 5,500 tons. Simultaneously, the demand for nonrenewable energy resources would decrease by 7,931,520 MJ eq. and the GWP would be reduced by 1,516 tons $\mathrm{CO}_{2}$ eq.

\subsection{Environmental benefits from loss treatments}

The environmental benefits of using potato losses as animal feed or biogas were relatively large due to the low impacts of potato losses especially at early stages of the supply chain. The use of potato losses as animal feed might even overcompensate the terrestrial ecotoxicity so that, in total across the entire supply chain, a net benefit would occur as compared with complete human consumption. However, this result does not imply that deducting potatoes from the food market and using them as animal feed would be ecologically reasonable. In general, preventing potato losses allowed a greater environmental impact reduction than treating potato losses. These findings are in line with Gentil et al. (2011), who stated that waste prevention plays a significant role in emission reduction and climate change mitigation. Also, the results of a study conducted by Bernstad Saraiva Schott and Andersson (2015) suggest that we should rather focus on waste minimization than just on "the collection and treatment of waste that already has been generated and provide quantitative estimates of the climate related benefits from such strategies." 


\subsection{Strength and limitations}

Our study focused on the environmental impacts of potato losses across the entire potato supply chain. This single product view allowed a detailed analysis of the environmental hotspots and the driving forces. Most of the used data were collected especially for the purposes of this study and, thus, represented the general situation in Switzerland. Nonetheless, our study was limited to six scenarios to reduce losses and simultaneously improve the ecological performance of the entire potato supply chain. We do not know anything about the economic and social consequences of the losses. Therefore, a complete sustainability assessment is essential (Seuring and Müller, 2008). To improve the sustainability of products, Seuring and Müller (2008) assigned a central role to LCA: If impacts and requirements along the product life cycle are well known, the focal company (which could be the retailers in our case) and its suppliers can improve the performance of the whole supply chain. Therefore, our study can be seen as a first step towards a "sustainable" potato supply chain. In the future, the three investigated loss treatments need to be evaluated concerning their social and monetary costs.

\section{Conclusions}

The study identified the terrestrial ecotoxicity as the impact category for which actions on potato losses have the highest reduction potential. However, although $39 \%$ of the total terrestrial ecotoxicity was caused by potatoes that would not be consumed by humans, the impact reduction potential through loss reduction did not exceed $21 \%$ whereas that through loss treatments was greater. Overall, terrestrial ecotoxicity was strongly influenced by direct field emissions (e.g., from fertilizers, pesticides, heavy metals). Furthermore, $31 \%$ of each the total GWP and human toxicity were caused by losses. According to the loss reduction scenarios, potential improvements were rather low $(<11 \%)$ and loss treatments offered comparatively greater impact reduction potentials. Even in the current situation, $31 \%$ of the caused GWP and $16 \%$ of the human toxicity were compensated. In the impact category demand for nonrenewable energy resources, $23 \%$ were caused by potato losses. The loss reduction scenarios reduced the energy demand by maximal $7 \%$. In contrast, if all potato losses were to be treated within a biogas plant, $48 \%$ of the whole energy demand could be compensated. In the current loss treatment situation, the whole energy demand was reduced by $24 \%$, as the majority of losses are fed to animals $(68 \%)$. The least improvements could be realized for the impact category aquatic ecotoxicity, $27 \%$ of which were caused by losses. According to the loss reduction scenarios, the whole aquatic ecotoxicity could be reduced by $9 \%$ in the best case (Mix) or even be increased by $1 \%$ (A5). Also, the treatment of potato losses solely in an incineration plant would increase the total impact in this category by $51 \%$. In the current loss treatment situation, as the share of losses that 
are incinerated was $29 \%$, the whole aquatic ecotoxicity impacts were reduced by $10 \%$ due to the combination of the three loss treatments.

In summary, as potato losses are reused in Switzerland, the environmental impacts caused by losses are reduced or even overcompensated. These findings do not imply that people should not care about losses. Especially losses occurring at private households are meaningful. They have the highest impacts per kilogram loss (8-42 times as high as the impacts of losses occurring at agricultural production) and are usually incinerated, thereby increasing human toxicity and terrestrial and aquatic ecotoxicity. The potential of loss reduction scenarios with single measures is rather low, but a combination of these measures might yield in considerable ecological improvements. Especially in combination with specific loss treatments, they can improve the performance of the entire potato supply chain.

\section{Acknowledgments}

We thank the Swiss National Science Foundation (SNSF) for the financial support and all organizations and contact people for delivering information.

\section{References}

Abeliotis, K., Detsis, V., Pappia, C., 2013. Life cycle assessment of bean production in the Prespa National Park, Greece. Journal of Cleaner Production 41, 89-96.

Agridea, 2012. Deckungsbeiträge. Agridea, Lindau/Lausanne.

Agridea, 2015. Email communication with Maya Hiltpold about feed rations for ruminants with and without potatoes.

Andersson, K., Ohlsson, T., Olsson, P., 1998. Screening life cycle assessment (LCA) of tomato ketchup: a case study. Journal of Cleaner Production 6, 277-288.

Bernstad Saraiva Schott, A., Andersson, T., 2015. Food waste minimization from life-cycle perspective. Journal of Environmental Management 147, 219-226.

BFE, 2014. Schweizerische Gesamtenergiestatistik 2013. Bundesamt für Energie BFE, CH-3003 Bern.

BFS, 2012. Schweizer Landwirtschaft - zwischen Moderne und Tradition, Landwirtschaftliche Betriebszählung: Zusatzerhebung 2010. Bundesamt für Statistik BFS, Neuchâtel.

BFS, 2015. Mobilität und Verkehr, Taschenstatistik 2015. Bundesamt für Statistik BFS, Neuchâtel.

Björklund, A., 2002. Survey of approaches to improve reliability in LCA. Int. J. LCA 7, 64-72.

Bystricky, M., Alig, M., Nemecek, T., Gaillard, G., 2014. Ökobilanz ausgewählter Schweizer Landwirtschaftsprodukte im Vergleich zum Import, Agroscope Science. Agroscope, Zürich.

Eriksson, M., 2012. Retail Food Wastage - a Case Study Approach to Quantities and Causes. Department of Energy and Technology, Uppsala.

Frischknecht, R., Jungbluth, N., Althaus, H.-J., Doka, G., Dones, R., Heck, T., Hellweg, S., Hischier, R., Nemecek, T., Rebitzer, G., Spielmann, M., Wernet, G., 2007. Overview and Methodology - Data v2.0, ecoinvent report. Swiss Centre for Life Cycle Inventories, Dübendorf.

Garnett, T., 2011. Where are the best opportunities for reducing greenhouse gas emissions in the food system (including the food chain)? Food Policy 36, 23-32.

Gentil, E.C., Gallo, D., Christensen, T.H., 2011. Environmental evaluation of municipal waste prevention. Waste Management 31, 2371-2379.

Gruber, L.M., Brandstetter, C.P., Bos, U., Lindner, J.P., 2014. LCA study of unconsumed food and the influence of consumer behavior, in: Schenck, R., Huizenga, D. (Eds.), 9th International Conference on Life Cycle Assessment in the Agri-Food Sector, San Francisco, USA, pp. 489-499.

Guinée, J., Gorrée, M., Heijungs, R., Huppes, G., Kleijn, R., de Koning, A., van Oers, L., Wegener Sleeswijk, A., Suh, S., de Haes, H.A.U., de Bruijn, H., van Duin, R., Huijbregts, M.A.J., 2001. Life cycle assessment - An operational guide to the ISO standards, Final report. Leiden University (CML), Leiden, The Netherlands. 
Heger, M., Robin, F., Heck, W., 2010. GOLDOR BAIT® - Ein neues Ködergranulat zur Bekämpfung von Drahtwürmern in verschiedenen Kulturen, Humboldt-Universität Berlin.

Hischier, R., Weidema, B., Althaus, H.-J., Bauer, C., Doka, G., Dones, R., Frischknecht, R., Hellweg, S., Humbert, S., Jungbluth, N., Köllner, T., Loerincik, Y., Margni, M., Nemecek, T., 2010. Implementation of Life Cycle Impact Assessment Methods, ecoinvent report. Swiss Centre for Life Cycle Inventories, Dübendorf.

IPCC, 2007. Climate Change 2007: Impacts, Adaptation and Vulnerability, Contribution of Working Group II to the Fourth Assessment Report of the IPCC. Cambridge University Press, Cambridge, UK.

ISO 14040, 2006. Environmental management - Life cycle assessment - Principles and framework.

Jones, C.D., Fraisse, C.W., Ozores-Hampton, M., 2012. Quantification of greenhouse gas emissions from open field-grown Florida tomato production. Agricultural Systems 113, 64-72.

Jungbluth, N., 2000. Umweltfolgen des Nahrungsmittelkonsums: Beurteilung von Produktmerkmalen auf Grundlage einer modularen Ökobilanz, Diss. ETH. Eidgenössischen Technischen Hochschule Zürich.

Jungbluth, N., Chudacoff, M., Dauriat, A., Dinkel, F., Doka, G., Faist Emmenegger, M., Gnansounou, E., Kljun, N., Schleiss, K., Spielmann, M., Stettler, C., Sutter, J., 2007. Life Cycle Inventories of Bioenergy, ecoinvent report. Swiss Centre for Life Cycle Inventories, Dübendorf, $\mathrm{CH}$.

Jungbluth, N., Tietje, O., Scholz, R.W., 2000. Food Purchases: Impacts from the Consumers' Point of View Investigated with a Modular LCA. LCA Case Studies 5, 134-142.

Karakaya, A., Özilgen, M., 2011. Energy utilization and carbon dioxide emission in the fresh, paste, whole-peeled, diced, and juiced tomato production processes. Energy 36, 5101-5110.

Keiser, A., Häberli, M., Schnyder, E., Berchier, P., 2007. Einfluss des Anbausystems, der Anbautechnik und des Standorts auf die Kartoffelqualität in der Schweiz. Schweizerische Hochschule für Landwirtschaft (SHL), CH3052 Zollikofen.

Kellenberger, D., Althaus, H.-J., Jungbluth, N., Künniger, T., 2007. Life Cycle Inventories of Building Products, Final report ecoinvent data v2.0. Swiss Centre for Life Cycle Inventories, Dübendorf.

Klöpffer, W., Grahl, B., 2009. Ökobilanz (LCA): Ein Leitfaden für Ausbildung und Beruf. Wiley-VCH Verlag $\mathrm{GmbH} \& \mathrm{Co}$. KGaA, Weinheim.

Manfredi, M., Vignali, G., 2014. Life cycle assessment of a packaged tomato puree: a comparison of environmental impacts produced by different life cycle phases. Journal of Cleaner Production 73, 275-284.

Moll, S., Watson, D., 2009. Environmental Pressures from European Consumption and Production - A study in integrated environmental and economic analysis. European Topic Centre on Sustainable Consumption and Production.

Mouron, P., Nemecek, T., Scholz, R.W., Weber, O., 2006. Management influence on environmental impacts in an apple production system on Swiss fruit farms: Combining life cycle assessment with statistical risk assessment. Agriculture, Ecosystems and Environment 114, 311-322.

Nemecek, T., Kägi, T., Blaser, S., 2007. Life Cycle Inventories of Agricultural Production Systems, Final report ecoinvent v2.0 Swiss Centre for Life Cycle Inventories, Dübendorf.

Notarnicola, B., Hayashi, K., Curran, M.A., Huisingh, D., 2012. Progress in working towards a more sustainable agri-food industry. Journal of Cleaner Production 28, 1-8.

Omya AG, 2009. Sicherheitsdatenblatt gemäß 2001/58/EG Gro Stop HN.

Ponsioen, T., Blonk, H., 2011. Case studies for more insight into the methodology and composition of carbon footprints of table potatoes and chips. Blonk Environmental Consultants, $2801 \mathrm{CA}$ Gouda.

Schmid, D., Lenggenhager, P., Steingruber, E., 2010. Wirtschaftlichkeit der Paralandwirtschaft am Beispiel der Direktvermarktung. ART-Bericht 737.

Scholz, K., Eriksson, M., Strid, I., 2015. Carbon footprint of supermarket food waste. Resources, Conservation and Recycling 94, 56-65.

Seuring, S., Müller, M., 2008. From a literature review to a conceptual framework for sustainable supply chain management. Journal of Cleaner Production 16, 1699-1710.

Sonesson, U., Davis, J., Ziegler, F., 2010. Food production and emissions of greenhouse gases. SIK, Gothenburg. Sonesson, U., Janestad, H., Raaholt, B., 2003. Energy for Preparation and Storing of Food-Models for Calculation of Energy Use for Cooking and Cold Storage in Households, SIK-Report. SIK-The Swedish Institute for Food and Biotechnology, Göteborg, Sweden.

Swiss Centre for Life Cycle Inventories, 2010. Ecoinvent database v2.2, Dübendorf, CH.

Takata, M., Fukushima, K., Kino-Kimata, N., Nagao, N., Niwa, C., Toda, T., 2012. The effects of recycling loops in food waste management in Japan: Based on the environmental and economic evaluation of food recycling. Science of the Total Environment 432, 309-317.

Uhlmann, S., Leppack, E., Sauer, N., 2003. Aufbereitung von Kartoffeln: Kalkulationsdaten KTBL-Schr.-Vertrieb im Landwirtschaftsverl., Münster.

Willersinn, C., Mack, G., Mouron, P., Keiser, A., Siegrist, M., 2015. Quantity and quality of food losses along the Swiss potato supply chain: Stepwise investigation and the influence of quality standards on losses. Waste Management 46, 120-132. 